\title{
On the Aggregate Implications of Removing Barriers to Formality
}

\author{
Catalina Granda and Franz Hamann
}

\begin{abstract}
This article examines the aggregate implications of several policies aimed at removing barriers to formality. To this end, we build a dynamic equilibrium model in which heterogeneous agents choose to work for a wage or operate a technology in the formal or informal sector, based on the costs and benefits associated with these occupational choices. Formality entails compliance with taxes, a minimum wage scheme, and firm operation costs but has a productivity advantage stemming from access to external finance and legal enforcement mechanisms. Informal activities avoid taxes and regulations without detection or punishment. The simulation results suggest that eliminating formal operation fees leads to firm formalization, earnings redistribution, and increases in total factor productivity and welfare. In addition, eliminating the income tax reduces labor informality. These two policies, taken together, generate full formalization and gains in redistribution, efficiency, and welfare that are even greater than when all the barriers to formality are jointly removed. In contrast, eliminating the minimum wage has strong adverse effects on labor formalization and little impact on productivity. Eliminating the payroll tax leaves the occupational composition nearly unchanged and productivity and welfare as well. (JEL E26, H20, J30, L26, O17)
\end{abstract}

Federal Reserve Bank of St. Louis Review, Second Quarter 2020, 102(2), pp. 203-20.

https://doi.org/10.20955/r.102.203-20

\section{INTRODUCTION}

An extensive phenomenon worldwide, but especially in developing economies, is the existence of large informal sectors. Indeed, Schneider, Buehn, and Montenegro (2010) report average sizes of over 40 percent of gross domestic product (GDP) for Sub-Saharan Africa, Latin America, and the Caribbean, which contrast with about 17 percent in high-income Organisation for Economic Co-operation and Development (OECD) countries. While both

Catalina Granda is an associate professor of economics at the Universidad de Antioquia. Franz Hamann is director of the department of macroeconomic modeling at Banco de la República. The authors thank one anonymous referee for very detailed suggestions. Catalina Granda gratefully acknowledges financial support from the program "Inclusión productiva y social: programas y políticas para la promoción de una economía formal," code 60185, which conforms to the Alianza EFI - Economía Formal Inclusiva, under the contingent recovery grant No. FP44842-220-2018. All errors and omissions are our own. Amalia Rodríguez provided valuable assistance in microdata processing.

(c) 2020, Federal Reserve Bank of St. Louis. The views expressed in this article are those of the author(s) and do not necessarily reflect the views of the Banco de la República or its board of directors, the Federal Reserve System, the Board of Governors, or the regional Federal Reserve Banks. Articles may be reprinted, reproduced, published, distributed, displayed, and transmitted in their entirety if copyright notice, author name(s), and full citation are included. Abstracts, synopses, and other derivative works may be made only with prior written permission of the Federal Reserve Bank of St. Louis. 


\section{Figure 1}

\section{Saving Motives by Sector (percent)}

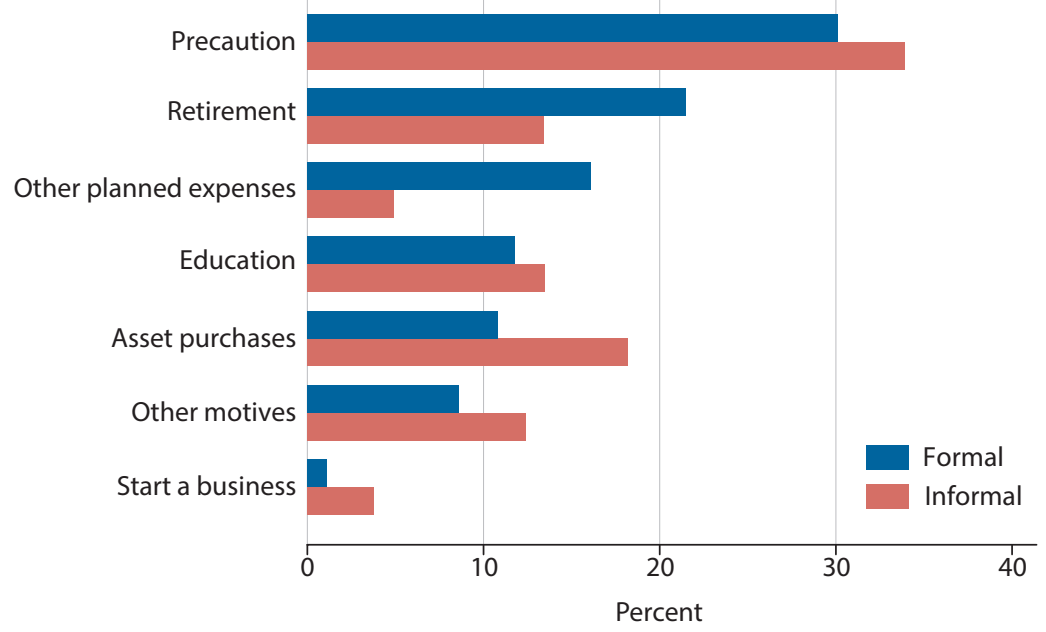

NOTE: See note 2 for the categorization of motives.

SOURCE: Authors' calculations based on the 2013 wave of the ELCA survey.

firms and workers often operate in the informal sector to avoid cumbersome regulations and taxation, there are costs-such as lack of access to the judicial and legal system and to financial markets (including insurance against retirement income risk and other risks) - that are likely to exert a negative influence on productivity, growth, and welfare.

In view of the potential advantages of overcoming the informal sector, this article develops a framework to quantitatively examine the macroeconomic implications of several policies aimed at removing barriers to formality. To this end, we build a dynamic equilibrium model wherein heterogeneous agents choose whether to operate in the formal sector or the informal sector. These decisions result from analyzing the costs and benefits associated with such occupational choices and take into account a variety of policies. Thus, individuals in the formal sector must comply with taxes, a minimum wage, and firm operation costs but also have a productivity advantage stemming from access to external finance and legal contract enforcement mechanisms. Individuals in the informal sector avoid taxes and regulations without being audited and punished.

In the model, there are financial market imperfections that result in agents' inability to insure against idiosyncratic uncertainty, thus inducing them to save for precautionary reasons. This behavior is consistent with evidence from developing countries suggesting that buffering unexpected events seems to be the main motivation for saving among low- and middle-income individuals. In particular, using data from the Colombian Longitudinal Survey (henceforth ELCA),, we find this to be the most important motive irrespective of the occupation and/or sector of operation. -2 Moreover, according to Figure 1, individuals employed in the informal sector save more for precautionary reasons than those employed in the formal sector. $\underline{3}$ 
The model is calibrated to match important aspects of the Colombian microdata, as this developing country is highly regulated (considering both labor and entry regulations), with extensive informality at the firm level and in the labor market. ${ }^{4}$ This procedure allows us to assess the impact of a broad array of highly debated formalization policies on the economy's extent of informality, productivity, and welfare. Specifically, the policies considered involve eliminating labor taxation (i.e., payroll and income), fixed costs of formal operation, and the minimum wage.

The simulation results suggest that eliminating both the income tax and the fixed costs of formal operation substantially improves the occupational composition. Indeed, eliminating the fixed costs of formal operation leads to firm formalization, earnings redistribution, and increases in aggregate efficiency and welfare. In turn, reducing the income tax rate to zero is an extremely effective policy for promoting labor formality, but it is inconsequential for earnings concentration and productivity. These two policies, taken together, generate full formalization and gains in redistribution and efficiency that are even greater than when all the barriers to formality are jointly removed.

In contrast, eliminating the payroll tax and the minimum wage is not beneficial for overcoming the informal sector and improving aggregate efficiency. With no payroll tax, both labor and firm informality remain nearly unchanged, as do productivity and welfare. Further, eliminating the minimum wage has strong adverse effects on the formal sector and little impact on efficiency. These results can be rationalized by the insurance role that a nonbinding minimum wage plays in our model, which mitigates financial incompleteness for low-productivity individuals who work in the formal sector.

Some of the policies considered in this article have been widely analyzed at an empirical level. Indeed, a number of studies have shown that high nonwage costs and wage inflexibility associated with the minimum wage discourage formal employment and lead to high informal employment rates (see, for instance, Bell, 1997; Kugler and Kugler, 2009; and MondragónVélez, Peña, and Wills, 2010). Further, the literature on entry regulation and formalization of microenterprises in developing countries suggests that reforms intended to simplify business registration in the past decades have resulted in modest increases in the number of formal firms (see Bruhn and McKenzie, 2014, and the references therein).

Theoretically, this article is related to a strand of the literature that analyzes the aggregate effects of different formalization policies in developing countries. In a recent study, Ulyssea (2018) develops an equilibrium model wherein formal firms face fixed costs of registration and comply with revenue and labor taxes, yet they may avoid the latter by hiring informal workers. Informal firms in turn are able to evade all taxes and regulations, but they face a detection cost. The author uses the model to conduct counterfactual analyses of several policies toward informality, considering two experiments of interest: (i) reducing formal sector entry costs and (ii) a payroll tax cut. These experiments show that firm and labor informality need not move in the same direction as a result of policy changes. In particular, he finds that lowering registration costs is not effective in reducing labor informality and that lowering the payroll tax reduces the number of informal firms only slightly. Overall, his findings suggest that fewer informal firms and workers are not necessarily associated with higher output, total factor productivity (TFP), or welfare. 


\section{Granda and Hamann}

Furthermore, Ulyssea (2010) examines the role of labor market institutions and entry regulations in the size of the informal sector and in overall labor market performance. To that end, he develops a two-sector matching model that incorporates the main features of developing countries' labor and entry regulations. The simulation results indicate that reducing payroll taxes and increasing unemployment benefits are not effective policies for reducing informality and improving labor market indicators. In contrast, lowering the costs of entry into the formal sector significantly reduces the size of the informal sector and substantially improves employment composition. The author concludes that the best option for decreasing informality and improving labor market performance and welfare would be to reduce the formal sector's entry costs, instead of intensifying punishment and auditing informal activities.

Moreover, this article is related to a number of recent studies that quantitatively examine the impact on economic development of financial market imperfections and costs of creating and operating formal sector firms. D'Erasmo and Moscoso Boedo (2012) propose a general equilibrium model of firm dynamics, finding that countries with low degrees of debt enforcement and high costs of formality are characterized by low allocative efficiency and a large share of output produced by low-productivity informal firms. Somewhat similarly, Antunes and Cavalcanti (2007) construct a model with three occupational choices (worker, formal entrepreneur, or informal entrepreneur) and inequality in wealth and entrepreneurial ideas to assess how much of the cross-country variation in the size of the informal sector and per capita income can be attributed to entry barriers and limited enforcement of financial contracts. These authors find, among other results, that contract enforcement and regulation costs interact in nonlinear ways and cannot account for much of the output differences across countries.

In the same vein, Lopez-Martin (2019) builds a model of entrepreneurship with the same three occupational choices and financial frictions to evaluate the impact of several formalization policies. His findings suggest that eliminating registration costs has modest effects but that improving access to credit is key to reducing the informal sector size and increasing aggregate TFP and output per worker. Lastly, Araujo and Rodrigues (2016) analyze the role of taxation and credit constraints on formalization, aggregate efficiency, and income distribution. These authors find that, taken together, the distortions included in their model are able to generate substantial inefficiency and inequality. Further, while the efficiency implications of removing these distortions largely come from borrowing constraints, they find that tax rates are the main driver behind inequality reductions.

The article is organized as follows. The main aspects of the model economy are described in Section 2, whereas an assessment of its quantitative performance is left to Section 3. In Section 4, we examine how the informal sector and several macroeconomic aggregates behave in the face of changes in the policy parameters mentioned above. Section 5 concludes.

\section{THE MODEL}

We propose a model of occupational choice featuring taxation, wage rigidities, and fixed costs of formal operation. The model economy is small and open and financial markets are incomplete, but individuals use a risk-free asset to insure against idiosyncratic uncertainty. Our analysis focuses on the stationary equilibrium. 
The economy is populated by a continuum of infinitely lived individuals who are heterogeneous with respect to their productivity $z$, their occupation $o$, and their wealth $a$. While the latter two are chosen endogenously by forward-looking decisions, the former is an exogenous stochastic process that evolves over time according to the Markov transition probabilities $p\left(z^{\prime}, z\right)=\operatorname{Pr}\left(z_{t+1} \mid z_{t}\right)$. Depending on an individual's occupation, $z$ can be regarded as entrepreneurial ability or units of labor efficiency.

In each period, individuals choose whether to work for a wage or to operate a business in one of two sectors: a formal sector encompassing all production produced strictly following all regulations in place and an informal sector encompassing all production unreported to the tax authorities and conducted with workers not hired under a regular contract. Their choices are based on the comparative advantages associated with each occupational status as described below.

Specifically, at the beginning of each period, individuals are either entrepreneurs or workers in either the formal or informal sector,

$o \in \mathcal{O}=\{$ formal entrepreneur, informal entrepreneur, formal worker, informal worker $\}$,

and hold some level of a risk-free asset, $a \in \mathcal{A}=\left\{a_{0}<a_{1}<\ldots<a_{n_{a}}\right\}$, such that their asset choices are bounded by the no-borrowing constraint $a_{0} \geq 0$.

\subsection{Technology and Preferences}

Individuals discount their future utility using the discount factor $\beta \in(0,1)$. Their problem is to maximize lifetime utility as described by

$$
U=E_{0} \sum_{t=0}^{\infty} \beta^{t} u(c t)
$$

where per-period utility exhibits constant relative risk aversion:

$$
u\left(c_{t}\right)=\frac{c_{t}^{1-\sigma}-1}{1-\sigma} .
$$

To this end, individuals face two types of decisions: a static one, whereby entrepreneurs choose the optimal factor demands, and a dynamic one, which involves an agent's occupation $o^{\prime}$ and asset holdings $a^{\prime}$ next period.

As for the static decision, an entrepreneur with ability $z$ uses labor to produce a homogeneous consumption good. At the beginning of each period, the entrepreneur operates the technology $f^{s}(\cdot)$ in either of the two sectors, $s=\{f, i\}$. The entrepreneur's production technology is of the form

$$
f^{s}\left(z_{t}, n_{t}^{s}\right)=z_{t} Z^{s}\left(n_{t}^{s}\right)^{\mu}
$$

where $n_{t}^{s}$ is the level of labor used in period $t$ and $Z^{s}$ is a sector-specific productivity parameter such that $Z^{f}>1$ and $Z^{i}=1$. Further, it is assumed that $0<\mu<1$, meaning that production exhibits decreasing returns to scale. Total production is defined as $y_{t}^{\text {tot }}=\sum_{s} y_{t}^{s} \cdot \underline{\underline{5}}$ 
This specification of production technologies implies that formal sector firms enjoy a productivity advantage relative to informal sector firms. Such an advantage constitutes an incentive for entrepreneurs to operate formally and can be thought of as stemming from the ability to engage in legal contracts and access infrastructure facilities and financial markets, among others (Perry et al., 2007; Dabla-Norris, Gradstein, and Inchauste, 2008). $\underline{6}$

\subsection{Individual's Problem}

The incentives individuals face depend on whether they decide to remain as workers in either of the two sectors or switch and become a formal entrepreneur. In particular, if an individual chooses to become a formal entrepreneur, he must pay a creation cost for his business $\eta$, which is denominated in units of the consumption good.

Also, a formal entrepreneur hires each labor unit at a wage $w^{f}$ and pays constant tax rates on profits, $\tau^{c} \geq 0$, and payroll, $\tau_{f}^{w} \geq 0$. An entrepreneur operating in the informal sector, in contrast, must pay a wage per unit of labor of $w^{i}$ and pays no taxes $\left(\tau^{c}=\tau_{i}^{w}=0\right)$.

Likewise, an individual who decides to be a formal worker earns a wage $w^{f}=\max \left\{w_{\min }, w z\right\}$, the maximum wage between the minimum wage and a labor efficiency wage, and pays a fixed tax rate on labor income $\tau^{y} \geq 0$. If the individual instead chooses to work informally, the individual is paid the wage $w^{i}=w z$ and charged no taxes.

There are no switching costs on labor supply. Moreover, irrespective of their sector of operation, entrepreneurs choosing to liquidate their formal businesses and move to another occupation face no exit costs. The government cannot distinguish an individual's occupation, and hence informal activities are neither monitored nor punished. All revenue collected from taxes and operation costs is used for unproductive activities.

Accordingly, an individual's earnings depend on the individual's current occupation and can be summarized in the following reward function?

$$
r(z, o)=\left(\begin{array}{ll}
\left(1-\tau^{c}\right) \pi^{f}(z), & o=\text { formal entrepreneur } \\
\pi^{i}(z), & o=\text { informal entrepreneur } \\
\left(1-\tau^{y}\right) w^{f}, & o=\text { formal worker } \\
w^{i}, & o=\text { informal worker }
\end{array}\right.
$$

where the indirect profit function from running a business in sector $s, \pi^{s}$, is defined as

$$
\pi^{s}\left(z ; w^{s}\right)=\max _{n^{s}}\left\{f^{s}\left(z, n^{s}\right)-\left(1+\tau_{s}^{w}\right) w^{s} n^{s}\right\}
$$

and the associated labor demands are $n^{s}\left(z ; w^{s}\right)$ with $n^{s} \geq 0$.

Thus, the recursive representation of an individual's problem is given by the following Bellman equation: 


$$
\begin{gathered}
v(z, a, o)=\max _{c \geq 0, a^{\prime} \in \mathcal{A}, o^{\prime} \in \mathcal{O}}\left\{u(c)+\beta \sum_{z^{\prime}} p\left(z^{\prime}, z\right) v\left(z^{\prime}, a^{\prime}, o^{\prime}\right)\right\} \\
\text { subject to } \quad c+a^{\prime}=r(z, o)+R^{*} a-\eta 1_{\neg o^{\prime}} \\
a \geq 0,
\end{gathered}
$$

where $1_{\neg 0^{\prime}}$ is an indicator variable that equals 1 if an individual starts or continues operating a formal enterprise and zero otherwise. Note that $R^{*}$ is the gross rate of return on assets.

The value function $v$ is defined on three state variables: productivity, $z \in \mathcal{Z}$; net wealth, $a \in \mathcal{A}$; and occupation, $o \in \mathcal{O}$. The decision variables are current consumption, $c$, and net asset holdings and occupation next period, $a^{\prime} \in \mathcal{A}$ and $o^{\prime} \in \mathcal{O}$, respectively. Letting $\omega$ be the vector of state variables, $\omega=(z, a, o)$, the optimal policy function for the decision variables can be denoted by $x(\omega)=\left\{c(\omega), a^{\prime}(\omega), o^{\prime}(\omega)\right\}$. Accordingly, the controlled-state process of the justdescribed dynamic program is a Markov chain with transition probability matrix $\mathcal{P}$ and ergodic distribution $h$.

This framework implies that individuals save to smooth consumption. Note that earnings from all occupations are stochastic, but likely more so for informal workers and (both formal and informal) entrepreneurs. In this sense, labor market rigidities secure flat income flows and determine how many workers join the formal sector, in turn affecting how many join the informal sector. Put differently, for workers in the formal sector, the minimum wage policy provides insurance from the downside risk of stochastic productivity associated with entrepreneurship and informality. Such is the main benefit for formal workers, even though informal workers may earn more.

\subsection{Equilibrium}

Notice that the solution to the discrete dynamic program described above depends on the equilibrium values of the formal and informal wages $\left(w^{f}, w^{i}\right)$. In this regard, the minimum wage implies a lower bound on wages earned by workers in the formal sector. Thus, there is an individual productivity threshold below which lower-productivity workers earn a higher wage than they would have earned in the absence of the minimum wage. Since workers can move freely across sectors, however, formal and informal wages are determined endogenously by the mass of individuals willing to work in either sector at wages $w^{f}$ and $w^{i}$, respectively, relative to the labor demand by formal and informal entrepreneurs at those wages. To sum up, whereas $W_{\min }$ is taken as a parameter, $w^{i}$ and $w^{f}$ constitute an equilibrium outcome.

Let $\mathcal{O}_{f}$ and $\mathcal{O}_{i}$ be the sets of agents who optimally choose to be in the formal or informal sector, respectively. A stationary equilibrium for this economy consists of an invariant distribution $h$ of the state variables $\omega$; a set of policy functions $x(\omega)$; and labor decisions by entrepreneurs $\left\{n^{s}(z)\right\}$ such that, given wages $\left(w^{f}, w^{i}\right)$, tax rates $\left(\tau^{c}, \tau_{s}^{w}, \tau^{y}\right)$, and the cost of creating a formal firm $\eta$,

- individuals solve their optimization problem, the Bellman equation (1);

- the distribution $h$ is stationary: $h=\mathcal{P}^{\prime} h$; and

- both the formal and informal labor markets clear. 


\section{Granda and Hamann}

Note that the capital market does not necessarily clear. Excess capital supply is exported abroad, with no effect on the interest rate, in this small open economy.

\section{QUANTITATIVE PERFORMANCE}

\subsection{Calibration}

The model is calibrated to be consistent with a number of features of the Colombian economy. To this end, we divide the parameter vector into two groups. The first group includes preference parameters that are difficult to identify using our data and to which we assign values that are common in the dynamic general equilibrium literature. Accordingly, the period is set to one year so that the discount factor $\beta$ is equal to 0.972 ; also, the risk aversion coefficient $\sigma$ is set to 2 . These two values are within the ranges reported in studies of emerging market economies. $\frac{8}{}$

Furthermore, the first group takes into account the labor share, so we set $\mu$ to 0.06 for both the formal and informal sectors. This parameter value is also standard in the literature. Moreover, the real interest rate is set to 2.5 percent, a value close to the average ex-post consumer price index deflated yield on 3-month U.S. Treasury bills for the 1955-2014 period. This figure is 0.77 percent plus 158 basis points, the latter being the average Colombian emerging markets bond index (EMBI) spread for 2013.

Moving to the policy parameters, we assign both the labor income tax rate $\tau^{y}$ and the payroll tax rate $\tau_{f}^{y}$ in the formal sector a value of 0.15 . Also, for our benchmark calibration, we set the tax rate on profits equal to zero. The first two parameter values are low relative to the actual burden of taxation in Colombia and other Latin American countries (see Granda and Hamann, 2015, and Ulyssea, 2018), and their choice is arbitrary. We perform experiments changing these tax rates in a subsequent section.

The second group of parameters comprises the per-period fixed costs of formal operation $\eta$, the minimum wage $w_{\text {min }}$, the formal sector productivity advantage $Z^{f}$, and two parameters that characterize the variance and persistence of individual productivity.. These parameters are calibrated jointly to replicate the patterns of cross-sectoral occupations and earnings inequality computed for 2013 from two different data sources: the ELCA survey mentioned above and the National Household Survey (GEIH, for its initials in Spanish). $\underline{10}$ Specifically, the moments targeted are as follows:

(i) the share of entrepreneurs;

(ii) the share of informal entrepreneurs;

(iii) the share of informal workers;

(iv) the ratio of the minimum wage to median earnings; and

(v) the bottom 40 percent of the earnings distribution.

Note that by targeting the first three moments, we can also match their complements: the share of workers and the shares of both formal entrepreneurs and workers.

Table 1 summarizes the calibration strategy for all parameters. The calibrated value of the formal sector's fixed cost of operation $\eta$ is 0.12 , somewhat low compared with that found in cross-country studies. In particular, the World Bank's (various years) Doing Business project 


\section{Table 1}

\section{Summary of Calibrated Parameters}

\begin{tabular}{ccc|c} 
Parameter & Value & Description & Source \\
\hline$\beta$ & 0.972 & Discount factor & $\begin{array}{c}\text { Dynamic general } \\
\text { equilibrium literature }\end{array}$ \\
\hline$\sigma$ & 2.000 & Risk aversion coefficient & Arbitrary \\
\hline$R$ & 0.600 & Real interest rate & 3-month U.S. T-bills + EMBI 2013 \\
\hline$\tau_{f}^{w}$ & 1.025 & Payroll tax rate & \\
\hline$\tau^{y}$ & 0.150 & Labor income tax rate & Joint calibration \\
\hline$\eta$ & 0.150 & Fixed costs of formal operation & \\
\hline$w_{\min }$ & 0.120 & Minimum wage & \\
\hline$Z^{f}$ & 1.067 & Formal productivity advantage & Standard deviation \\
\hline$\sigma_{z}$ & 0.500 & of individual productivity & \\
\hline$\rho_{\mathrm{z}}$ & 0.900 & Persistence of individual productivity & \\
\hline
\end{tabular}

reports an average cost of registering a business in Colombia during the 2004-14 period of 16.5 percent of per capita income.

In contrast, the values of the parameters that characterize the process for individual productivity are relatively higher than the ones used in quantitative models to evaluate the misallocation costs of financial constraints. More specifically, these values are well above those of Lopez-Martin (2019), who takes the median of the cross-country estimates for these two parameters reported in Asker, Collard-Wexler, and Loecker (2014) for a large set of emerging economies.

\subsection{Model Assessment}

To evaluate the performance of the model economy, Table 2 displays some distributional statistics in stationary equilibrium, allowing for comparison with the ones obtained from the data. For the computations, informality is defined by the absence of contributions to the social security system, be it a healthcare or pension scheme. $\underline{11}$

In the first panel, we report some statistics for occupations. Note that both the ELCA and the GEIH encompass the whole range of occupational statuses. Thus, to compute the occupational and sectoral compositions so as to make moments from the benchmark economy comparable with those of the data, we have taken from the surveys data pertaining only to workers and entrepreneurs. It can be seen that the model does a good job in replicating the observed distribution of these two occupations across the formal and informal sectors.

The other panels report computations involving the minimum wage as a fraction of both mean and median earnings (second panel) and statistics for earnings shares held by all individuals in the corresponding quintile (third panel). Comparing the model with the data, it can be confirmed that the targeted moments are well matched. Specifically, the benchmark 
Table 2

Distributional Statistics

\begin{tabular}{lccc} 
& \multicolumn{2}{c}{ Data } & Model \\
\cline { 2 - 3 } & ELCA & GEIH & \\
\hline Workers & Occupations (percent) & 55.25 \\
\hline Formal & 60.47 & 55.70 & 71.58 \\
\hline Informal & 82.60 & 62.97 & 28.42 \\
\hline Entrepreneurs & 17.40 & 37.03 & 44.75 \\
\hline \multicolumn{1}{c}{ Formal } & 39.53 & 44.30 & 23.51 \\
\hline Informal & 39.01 & 14.44 & 76.49 \\
\hline & 60.99 & 85.56 & 0.494 \\
\hline Minimum wage/mean earnings & Minimum wage to earnings & 0.289 \\
\hline Minimum wage/median earnings & 0.566 & 0.614 & \\
\hline & 0.172 & 0.274 & 14.34 \\
\hline 0 to 40 percent & Earnings distribution (percent) & 12.21 \\
\hline 40 to 60 percent & 13.47 & 17.66 & 20.86 \\
\hline 60 to 80 percent & 15.43 & 14.34 & 52.59 \\
\hline 80 to 100 percent & 19.11 & 19.34 & \\
\hline NOTE: Data correspond to statistics for 2013. & & & \\
\hline
\end{tabular}

economy replicates the ratio of the minimum wage to median earnings and the share held by people in the bottom 40 percent of the earnings distribution relatively closely.

Last but not least, the calibration yields parameter values that allow the benchmark economy to resemble a number of moments that were not targeted explicitly. In the third panel of Table 2, the model is shown to generate earnings shares held by individuals in the middle to top quintiles that are roughly consistent with the evidence obtained from both the ELCA and the GEIH surveys.

\section{POLICY EXPERIMENTS}

In this section, we use the calibrated model to analyze a number of alternative policy scenarios. These policies traditionally have been proposed to remove barriers to formalization and include reductions in labor taxes, the minimum wage, and fixed costs of formal operation. We focus our attention on the impact on occupational choices across the formal and informal sectors, on the earnings distribution, and on production efficiency (i.e., TFP). $\underline{12}$ Further, we study the implications for social welfare by measuring consumption equivalent variations. 


\section{Table 3}

Policy Experiments: Removing Barriers to Formality

\begin{tabular}{|c|c|c|c|c|c|c|}
\hline & Benchmark & $\begin{array}{c}\text { No } \\
\text { fixed costs }\end{array}$ & $\begin{array}{l}\text { No minimum } \\
\text { wage }\end{array}$ & $\begin{array}{c}\text { No } \\
\text { payroll tax }\end{array}$ & $\begin{array}{c}\text { No } \\
\text { income tax }\end{array}$ & $\begin{array}{c}\text { No } \\
\text { interventions }\end{array}$ \\
\hline \multicolumn{7}{|c|}{ Occupations (percent) } \\
\hline Workers & 55.25 & 46.35 & 55.65 & 63.67 & 63.67 & 50.58 \\
\hline Formal & 71.58 & 78.38 & 0.00 & 57.14 & 100.00 & 44.69 \\
\hline Informal & 28.42 & 21.62 & 100.00 & 42.86 & 0.00 & 55.31 \\
\hline Entrepreneurs & 44.75 & 53.65 & 44.35 & 36.33 & 36.33 & 49.42 \\
\hline Formal & 23.51 & 100.00 & 24.03 & 39.78 & 39.78 & 100.00 \\
\hline Informal & 76.49 & 0.00 & 75.97 & 60.22 & 60.22 & 0.00 \\
\hline \multicolumn{7}{|c|}{ Minimum wage to earnings } \\
\hline Minimum wage/mean earnings & 0.494 & 0.438 & 0.000 & 0.482 & 0.476 & 0.000 \\
\hline Minimum wage/median earnings & 0.289 & 0.305 & 0.000 & 0.275 & 0.268 & 0.000 \\
\hline \multicolumn{7}{|c|}{ Earnings distribution (percent) } \\
\hline 0 to 40 percent & 14.34 & 15.58 & 12.14 & 14.05 & 14.49 & 14.32 \\
\hline 40 to 60 percent & 12.21 & 12.61 & 12.10 & 11.97 & 12.09 & 13.29 \\
\hline 60 to 80 percent & 20.86 & 21.27 & 21.46 & 20.96 & 20.67 & 21.85 \\
\hline 80 to 100 percent & 52.59 & 50.54 & 54.31 & 53.02 & 52.74 & 50.54 \\
\hline \multicolumn{7}{|c|}{ Production efficiency and welfare } \\
\hline TFP & 1.000 & 1.162 & 1.000 & 1.017 & 1.014 & 1.147 \\
\hline Welfare gain & & 0.047 & -0.026 & 0.024 & 0.051 & 0.065 \\
\hline
\end{tabular}

Thus, in what follows, we present the average welfare gains from each policy scenario, using the stationary distribution from the benchmark economy.

The first set of experiments we consider pertain to the elimination of each of the government interventions mentioned above (i.e., labor taxes, the minimum wage, and fixed costs of formal operation). These experiments are represented by reducing the corresponding policy parameters $\left(\tau^{y}, \tau_{s}^{w}, w_{\text {min }}, \eta\right)$ from their calibrated values to zero. The results from these reductions are presented in Table 3, wherein, to facilitate comparison, we reproduce the performance of the benchmark economy (second column) and that in which none of the concerned interventions is in place (last column).

As the table shows, the policies that encourage formalization the most are the elimination of the labor income tax and fixed costs of formal operation. These policies increase the appeal of joining the labor force and entrepreneurship in the formal sector, respectively, and thereby make formality an attractive choice. While these effects are in line with intuition, those from eliminating the minimum wage and the payroll tax seem a bit puzzling. Indeed, eliminating the minimum wage, rather than promoting formalization, leads to the opposite effect, as all 


\section{Granda and Hamann}

\section{Table 4}

Policy Experiments: Minimum Wage and Fixed Costs of Formal Operation

\begin{tabular}{|c|c|c|c|c|c|c|}
\hline & \multicolumn{3}{|c|}{$\eta=0$} & \multicolumn{3}{|c|}{$w_{\min }=0$} \\
\hline & $\tau^{y}=\tau_{f}^{w}=0.15$ & $\tau_{f}^{w}=0$ & $\tau^{y}=0$ & $\tau^{y}=\tau_{f}^{w}=0.15$ & $\tau_{f}^{w}=0$ & $\tau^{y}=0$ \\
\hline \multicolumn{7}{|c|}{ Occupations (percent) } \\
\hline Workers & 46.35 & 50.57 & 47.18 & 55.65 & 63.67 & 55.65 \\
\hline Formal & 78.38 & 58.40 & 100.00 & 0.00 & 0.00 & 40.83 \\
\hline Informal & 21.62 & 41.60 & 0.00 & 100.00 & 100.00 & 59.17 \\
\hline Entrepreneurs & 53.65 & 49.43 & 52.82 & 44.35 & 36.33 & 44.35 \\
\hline Formal & 100.00 & 100.00 & 100.00 & 24.03 & 39.78 & 24.03 \\
\hline Informal & 0.00 & 0.00 & 0.00 & 75.97 & 60.22 & 75.97 \\
\hline \multicolumn{7}{|c|}{ Minimum wage to earnings } \\
\hline Minimum wage/mean earnings & 0.438 & 0.405 & 0.408 & 0.000 & 0.000 & 0.000 \\
\hline Minimum wage/median earnings & 0.305 & 0.859 & 0.776 & 0.000 & 0.000 & 0.000 \\
\hline \multicolumn{7}{|c|}{ Earnings distribution (percent) } \\
\hline 0 to 40 percent & 15.58 & 15.54 & 16.09 & 12.14 & 12.04 & 12.41 \\
\hline 40 to 60 percent & 12.61 & 12.89 & 12.64 & 12.10 & 12.07 & 12.25 \\
\hline 60 to 80 percent & 21.27 & 21.44 & 21.23 & 21.46 & 21.42 & 21.51 \\
\hline 80 to 100 percent & 50.54 & 50.13 & 50.04 & 54.31 & 54.48 & 53.82 \\
\hline \multicolumn{7}{|c|}{ Production efficiency and welfare } \\
\hline TFP & 1.162 & 1.147 & 1.159 & 1.000 & 1.017 & 1.000 \\
\hline Welfare gain & 0.047 & 0.075 & 0.071 & -0.026 & 0.000 & -0.026 \\
\hline
\end{tabular}

workers become informal. As for eliminating the payroll tax, it does not imply qualitative changes in the sectoral and occupational compositions relative to the benchmark economy.

Furthermore, eliminating the fixed costs of formal operation turns out to be the policy that generates higher redistribution: It leads to the greatest decrease in the share of earnings held by the top 20 percent and to the greatest increase in the share held by the bottom 40 percent of income earners. In contrast, the policy that translates into higher earnings concentration is the elimination of the minimum wage, which generates the greatest increase in the share held by the top quintiles and the greatest decrease in the share held by the lowest ones. This result is to be expected given that removal of the minimum wage leaves wages entirely at the mercy of market forces and thereby ends the lower bound on earnings for low-productivity individuals.

Moreover, eliminating the fixed costs of formal operation is the most beneficial policy in terms of production efficiency, whereas eliminating the minimum wage is the least. Table 3 shows that eliminating the fixed costs of formal operation generates the greatest increases in 
TFP, while eliminating the minimum wage results in little to no change. In the former case, the TFP gains reflect variations in the occupational composition: All firms choose to operate in the formal sector, which by assumption is more productive, thus leading to an increase in aggregate efficiency. Similarly for the latter case, lack of variation in the entrepreneurial shares when all workers join the informal sector turns out to be inconsequential for overall productivity.

Note that all these effects take place whether removal of the interventions is implemented in isolation or combined with other policies such as payroll and/or income tax cuts (Table 4). In this regard, Table 3 suggests that increases in production efficiency are higher when the fixed costs of formal operation are dropped solely (third column) than when none of the policy distortions is in place (last column). Further, removing all the barriers to formality considered in this article does not necessarily imply the highest TFP increases.

As for social welfare, Table 4 shows that eliminating for formal firms both the fixed costs of operation and payroll tax at the same time leads to the greatest welfare gains. This contrasts with eliminating the minimum wage, from which, either alone or combined with other tax cuts, the welfare gains are negative to null (see Tables 3 to 5). The reason for this paradoxical result has to do with the insurance nature of the minimum wage, which mitigates financial incompleteness especially for low-productivity individuals in the formal sector. Thus, absent this insurance, these individuals are no longer able to smooth consumption and hence there is a welfare loss.

The findings above seem to contradict those from related empirical studies. In particular, Bruhn and McKenzie (2014) show that reforms intended to simplify business registration in developing countries have led to modest results in terms of formalization of microenterprises. Note, however, that the formal sector's fixed costs featured in our model pertain not only to entering but also to staying in this sector. Also, Kugler and Kugler (2009) find that payroll taxes always decrease formal employment or increase informal employment in the presence of downward rigidities from government-mandated minimum wages. The divergence in this case has to do with our model assumption that the minimum wage is not binding, which makes it easier for firms to pass on payroll tax rate changes to workers via wages.

Nonetheless, our results are in line with the model simulations of Ulyssea (2010), who finds that lowering the costs of entry into the formal sector significantly reduces informality and increases average productivity and welfare. In contrast, payroll tax cuts have little impact on employment composition and hence productivity and welfare exhibit only a slight improvement. Somewhat similarly, Ulyssea (2018) shows that reducing formal sector entry costs leads to a substantial fall in the share of informal firms but essentially no increase in the share of labor in the informal sector. However, the general equilibrium effects of this intervention imply reductions in aggregate TFP and welfare, which are the opposite of the findings presented here.

Likewise, our results are certainly in line with those of Araujo and Rodrigues (2016). These authors find that eliminating all distortions in their model can improve aggregate efficiency and reduce inequality considerably, largely because this causes entrepreneurs to switch to the formal sector. While most of the efficiency improvement comes from removing credit frictions, lower tax rates are the main driver of reduced inequality. Yet, contrary to our findings, they find that eliminating only the labor tax reduces inequality but also makes the economy less 


\section{Table 5}

\section{Further Experiments: Both Minimum Wage and Income Tax}

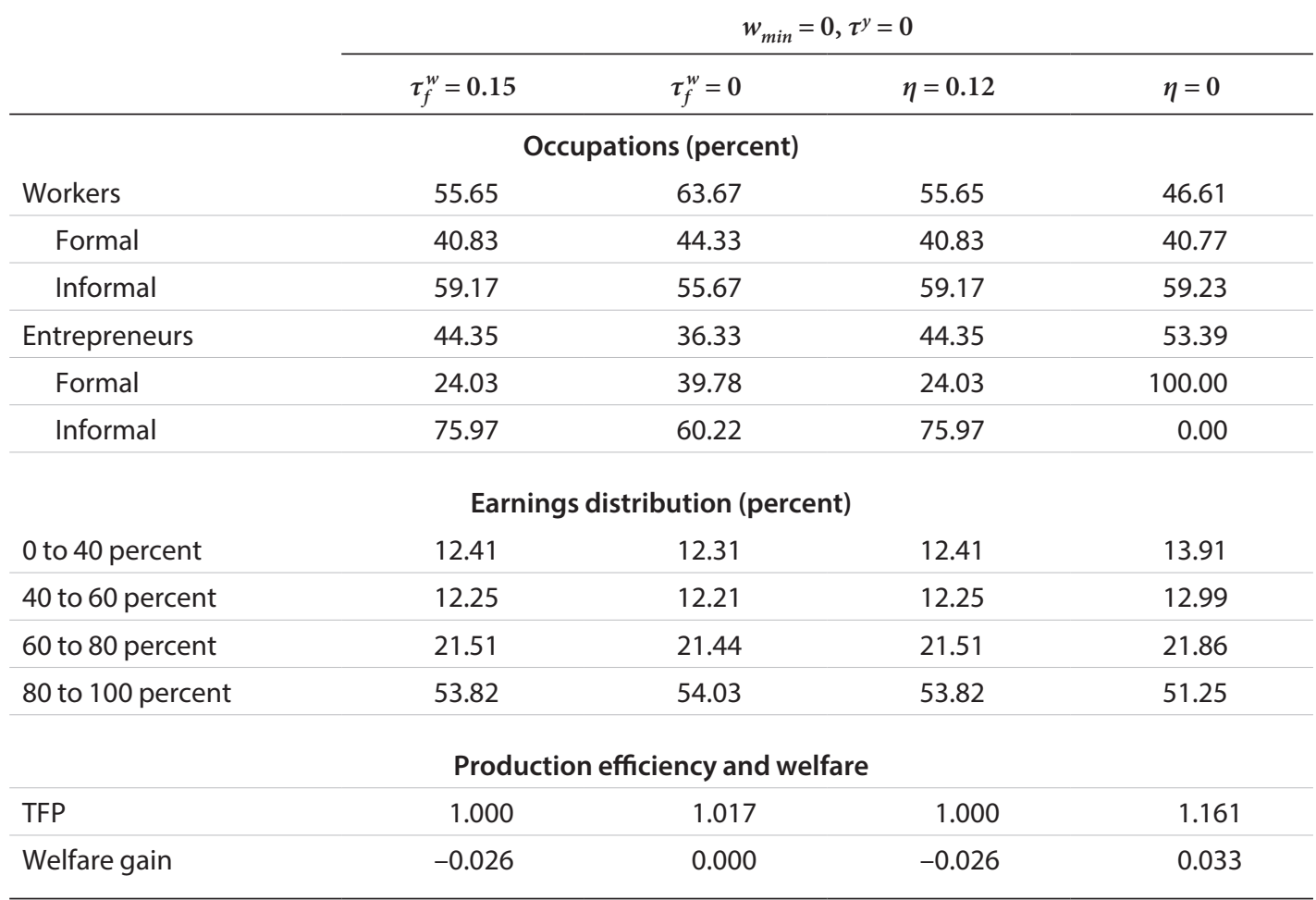

efficient. This is because it lowers gross wages, thereby inducing some entrepreneurs to migrate to the informal sector, where technology is less productive.

Consistent with the analysis above, it is worth noting that the only policy that results in full formalization, meaning that all workers and entrepreneurs join the formal sector, is one that eliminates both the labor income tax and the fixed costs of formal operation (fourth column of Table 4). This policy scenario also generates the greatest redistribution of earnings of all the scenarios considered in this article. Moreover, it implies both production efficiency and social welfare gains that are even greater than in the case of no government intervention whatsoever, although these certainly are not the highest among all the policy experiments.

Now, in view of the formalization effects of the policy just considered, we look at the implications of removing government interventions related to the minimum wage and the labor income tax at the same time. The results are displayed in the last column of Table 4 and in Table 5, where it can be seen that the joint removal of these interventions does not lead to full formalization or incentivize all workers to choose informality either. As regards redistribution, efficiency, and welfare, the consequences of eliminating the minimum wage are shown to be greater than those from eliminating only the labor income tax.

Finally, we also consider in Table 5 the impact of eliminating both the minimum wage and the income tax in conjunction with eliminating the payroll tax and the fixed costs of 
formal operation. Notice that of these experiments, only eliminating the fixed costs overcomes the impact of eliminating the minimum wage in all respects. This policy generates a pattern of earnings redistribution that, although not as remarkable as that observed in (columns 2 to 4 of) Table 4, is certainly the most prominent of all the scenarios considered therein. Further, this policy generates one of the highest increases in production efficiency as well as nonnegligible welfare gains.

\section{CONCLUDING REMARKS}

This article examines the aggregate implications of several policies aimed at removing barriers to formality. To this end, we develop a dynamic equilibrium model in which heterogeneous agents choose to work for a wage or operate a technology in the formal or informal sector, based on the costs and benefits associated with such occupational choices. Formality specifically entails compliance with taxes, a minimum wage scheme, and firm operation costs, but also has a productivity advantage from access to external finance and legal contract enforcement mechanisms. Informal activities avoid taxes and regulations without detection and punishment. Our model is calibrated to approximate some features of the Colombian economy in the early 2010s.

The simulation results suggest that a crucial determinant of informality is the magnitude of formal sector operation costs. High operation costs are associated with firm informality, increased earnings concentration, and aggregate efficiency and welfare losses. Further, eliminating the income tax is an extremely effective policy for reducing labor informality, but has no effect on the earnings distribution or total factor productivity. Jointly eliminating these two government interventions generates full formalization and leads to the greatest redistribution of earnings and even greater efficiency and welfare gains than eliminating all barriers to formality.

In stark contrast, eliminating only the minimum wage has strong adverse effects on labor formalization and welfare and is inconsequential for productivity. Also, reducing the payroll tax rate to zero has little impact on the occupational composition (i.e., informality remains nearly unchanged), efficiency, or welfare. When these two policies are combined, the implications on formalization and earnings distribution of eliminating the minimum wage are greater than those from eliminating only the payroll tax. These results are admittedly at odds with related empirical evidence (see, for instance, Bell, 1997, and Kugler and Kugler, 2009), but can be rationalized by the insurance role that the minimum wage plays in the model, which mitigates financial incompleteness for low-productivity workers in the formal sector.

Our approach, however, is not without limitations. Noticeable among these is how the presence of a binding minimum wage might affect the results presented here. This is especially important given the fact that the minimum wage is binding in some countries (see Neumark and Munguia Corella, 2019). Another interesting possibility would be the introduction of auditing and punishment of informal activities. Also, to improve our proposed model, a worthwhile specification would involve financial market incompleteness in the form of collateral constraints. These extensions would certainly make for a richer economic environment, 


\section{Granda and Hamann}

thus allowing us to shed further light on issues currently at the heart of academic and policy discussions.

\section{APPENDIX: A SOLUTION METHOD}

The model is solved by a combination of several numerical procedures. $\frac{13}{}$ First, we proceed by applying state-space discretization. The process for individual productivity $z \in \mathcal{Z}$ thus is discretized into 15 states following the method proposed by Rouwenhorst (1995). In the same vein, we construct a grid of 200 points for the asset level $a \in \mathcal{A}$. Likewise, there are four occupations $o \in \mathcal{O}$ in the model. Hence, the state space comprises $\mathcal{Z} \times \mathcal{A} \times \mathcal{O}$.

The equilibrium solution involves finding out the informal wage by applying the bisection method to an algorithm solving the dynamic programming problem. Such an algorithm takes a given informal wage to solve the entrepreneurs' static problem, compute individual utility, solve Equation (1) through policy function iteration, and calculate the excess demand for labor in the formal sector under the resulting stationary occupations. The bisection technique permits ascertaining the wage rate that nullifies the excess demand.

Once equilibrium convergence is reached, the ergodic distribution of combined assets and occupations is obtained. Then we compute the stationary values of the endogenous variables.

\section{NOTES}

1 Designed and carried out every three years by the Universidad de los Andes, this survey collects information from approximately 10,800 households representative of low- and middle-income socioeconomic groups at the national level as well as for five geographical regions in Colombia. For methodological details, see Bernal et al. (2014). Our analysis focuses on the second wave of the survey, conducted in 2013, and is based on responses by individuals from the urban module.

$\underline{2}$ The ELCA surveyors ask respondents their reasons for saving. We categorize the responses into six motives as follows: (i) retirement (for the future and old age); (ii) precaution (for unexpected events); (iii) asset purchases (to buy a house, a car, or other assets); (iv) to start a business (to start up or invest in a business); (v) education (to pay for their own education or that of their children); (vi) other planned expenses (for entertainment and recreational purposes); and (vii) other motives (for reasons different from the above).

$\underline{3}$ To measure the extent of informality, we apply the legal definition according to which the informal sector encompasses those individuals who do not make contributions to the social security system (i.e., either healthcare or pension schemes). However, to check the robustness of our computations, we use several specific defining criteria for firm and labor informality as presented in Granda and Hamann (2015, Appendix B). In all cases, results are similar to the ones using the legal definition.

4 Some estimates suggest that the informal sector in Colombia comprised about 37 percent of GDP and 74 percent of the labor force in the early to mid-2000s (see, respectively, Schneider, Buehn, and Montenegro, 2010, and Bernal, 2009).

5 Note that since both formally and informally produced goods are identical, they must have the same price in equilibrium, $q_{t}^{s} \equiv q_{t} \forall s$. For simplicity, this price is imposed along the solution and normalized to unity.

6 Also, this characterization might reflect the fact that the informal sector is typically unproductive compared with the formal sector (see La Porta and Shleifer, 2014).

$\underline{z}$ Time-t subscripts are omitted hereafter, with the prime symbol (') denoting a variable next period. 
$\underline{8}$ Note that the chosen value for the discount factor also allows a well-defined ergodic distribution of assets for all four occupations.

9 The process for individual productivity is discretized into 15 states using the Rouwenhorst (1995, Appendix 6) method. We assume that the probability of staying in the lowest state and the probability of remaining in the highest state are both equal.

10 The GEIH survey collects demographic and socioeconomic data from households in 13 metropolitan areas on a monthly basis. Our analysis makes use of seven specific chapters of the survey: Chapters B and C, about the dwelling and the households living therein; Chapter E, about people's general characteristics; Chapter F, compiled social security (health) information; Chapter G, about education; Chapter I, data about people employed; and Chapter $\mathrm{N}$, which includes information about other income sources. Also, following Mondragón-Vélez, Peña, and Wills (2010), we restrict the sample to those 15 to 70 years of age that report between 16 and 84 weekly hours worked on the main job. For further details, see Granda and Hamann (2015, Appendix B).

11 See note 3.

12 Note that TFP has been normalized to 1 in the benchmark model.

13 The computational implementation of the solution is based in part on some routines contained in the CompEcon toolbox (see Miranda and Fackler, 2002). The Matlab code files are available upon request.

\section{REFERENCES}

Antunes, Antonio R. and Cavalcanti, Tiago V. de V. "Start Up Costs, Limited Enforcement, and the Hidden Economy." European Economic Review, 2007, 51(1), pp. 203-24; https://doi.org/10.1016/j.euroecorev.2005.11.008.

Araujo, Julia P. and Rodrigues, Mauro. "Taxation, Credit Constraints and the Informal Economy." EconomiA, 2016, 17(1), pp. 43-55; https://doi.org/10.1016/j.econ.2016.03.003.

Asker, John; Collard-Wexler, Allan and De Loecker, Jan. "Dynamic Inputs and Resource (Mis)Allocation." Journal of Political Economy, 2014, 122(5), pp. 1013-63; https://doi.org/10.1086/677072.

Bell, Linda A. "The Impact of Minimum Wages in Mexico and Colombia." Journal of Labor Economics, 1997, 15(3), pp. S102-35; https://doi.org/10.1086/209878.

Bernal, Raquel. "The Informal Labor Market in Colombia: Identification and Characterization." Desarrollo y Sociedad, 2009, 63(1), pp. 145-208; https://doi.org/10.13043/dys.63.4.

Bernal, Raquel; Cadena, Ximena; Camacho, Adriana; Cárdenas, Juan Camilo; Fergusson, Leopoldo; Ibáñez, Ana Maria; Peña, Ximena and Rodriguez, Catherine. "Encuesta Longitudinal Colombiana de la Universidad de los Andes - ELCA 2013." Documento CEDE 2014-42, 2014.

Bruhn, Miriam and McKenzie, David. "Entry Regulation and the Formalization of Microenterprises in Developing Countries." World Bank Research Observer, 2014, 29(2), pp. 186-201; https://doi.org/10.1093/wbro/lku002.

Dabla-Norris, Era; Gradstein, Mark and Inchauste, Gabriela. "What Causes Firms to Hide Output? The Determinants of Informality." Journal of Development Economics, 2008, 85(1-2), pp. 1-27; https://doi.org/10.1016/j.jdeveco.2006.05.007.

D'Erasmo, Pablo N. and Moscoso Boedo, Hernan J. "Financial Structure, Informality and Development." Journal of Monetary Economics, 2012, 59(3), pp. 286-302; https://doi.org/10.1016/j.jmoneco.2012.03.003.

Granda, Catalina and Hamann, Franz. "Informality, Saving and Wealth Inequality in Colombia." IDB Working Paper 575, Inter-American Development Bank, 2015; https://doi.org/10.2139/ssrn.2581400.

Kugler, Adriana and Kugler, Maurice. "Labor Market Effects of Payroll Taxes in Developing Countries: Evidence from Colombia." Economic Development and Cultural Change, 2009, 57(2), pp. 335-58; https://doi.org/10.1086/592839.

La Porta, Rafael and Shleifer, Andrei. "Informality and Development." Journal of Economic Perspectives, 2014, 28(3), pp. 109-126; https://doi.org/10.1257/jep.28.3.109.

Lopez-Martin, Bernabe. "Informal Sector Misallocation." Macroeconomic Dynamics, 2019, 23(8), pp. 3065-098; https://doi.org/10.1017/S1365100517001055. 


\section{Granda and Hamann}

Miranda, Mario J. and Fackler, Paul L. Applied Computational Economics and Finance. The MIT Press, 2002.

Mondragón-Vélez, Camilo; Peña, Ximena and Wills, Daniel. "Labor Market Rigidities and Informality In Colombia." Economía, 2010, 11(1), pp. 65-95; https://doi.org/10.1353/eco.2010.0009.

Neumark, David and Munguia Corella, Luis Felipe. "Do Minimum Wages Reduce Employment in Developing Countries? A Survey and Exploration of Conflicting Evidence." NBER Working Paper 26462, National Bureau of Economic Research, 2019; https://doi.org/10.3386/w26462.

Perry, Guillermo E.; Maloney, William F.; Arias, Omar S.; Fajnzylber, Pablo; Mason, Andrew D. and Saavedra-Chanduvi, Jaime. Informality: Exit and Exclusion. The World Bank, 2007; https://doi.org/10.1596/978-0-8213-7092-6.

Rouwenhorst, K. Geert. "Asset Pricing Implications of Equilibrium Models of Business Cycles," in Thomas F. Cooley, ed., Frontiers of Business Cycle Research. Princeton University Press, 1995, pp. 294-330.

Schneider, Friedrich; Buehn, Andreas and Montenegro, Claudio. "New Estimates for the Shadow Economies All Over the World." International Economic Journal, 2010, 24(4), pp. 443-61; https://doi.org/10.1080/10168737.2010.525974.

Ulyssea, Gabriel. "Regulation of Entry, Labor Market Institutions and the Informal Sector." Journal of Development Economics, 2010, 91(1), pp. 87-99; https://doi.org/10.1016/.j.jeveco.2009.07.001.

Ulyssea, Gabriel. "Firms, Informality, and Development: Theory and Evidence from Brazil." American Economic Review, 2018, 108(8), pp. 2015-47; https://doi.org/10.1257/aer.20141745.

World Bank. Doing Business. Various years; http://www.doingbusiness.org/. 